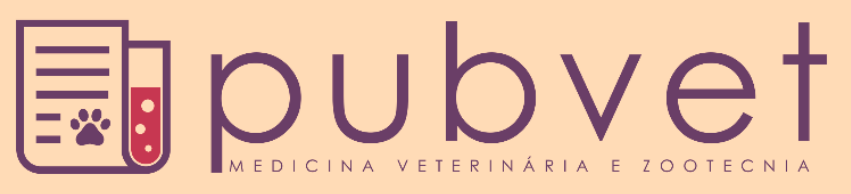

https://doi.org/10.31533/pubvet.v13n3a280.1-14

\title{
Criação de frangos de corte e acondicionamento térmico em suas instalações: Revisão
}

\author{
Maria Tereza Frageri Paulino ${ }^{1} \bullet$, Evandro Menezes de Oliveira $^{2}{ }^{\circ}$, Daiane de Oliveira \\ Grieser $^{30}$, Juliana Beatriz Toledo ${ }^{4 * 0}$ \\ ${ }^{1}$ Graduanda em Zootecnia, Universidade Estadual de Maringá. Departamento de Zootecnia. Maringá, PR-Brasil. \\ ${ }^{2}$ Doutorando do programa de pós-graduação em Zootecnia, Universidade Estadual de Maringá. Maringá, PR-Brasil. \\ ${ }^{3}$ Professora Universidade Federal do Sul e Sudeste do Pará. Departamento de Zootecnia. Xinguara, PA-Brasil. \\ ${ }^{4}$ Professora Universidade Estadual de Maringá. Departamento de Zootecnia. Maringá, PR-Brasil. \\ *Autor para correspondência, E-mail: juliana.b.toledo@gmail.com
}

\begin{abstract}
Resumo. A automatização total dos aviários e as inovações tecnológicas nas instalações de frangos de corte têm sido geradas ao logo dos anos, e vários modelos de galpões podem ser encontrados a campo com diferentes finalidades. Por ser um dos seguimentos mais modernos da criação animal a avicultura de corte cresce a cada ano e também a busca por melhorias nas instalações para acomodação das aves. Entretanto, para cada região devem ser observados os fatores meteorológicos que podem prejudicar a produção das aves, e a partir disso escolher o tipo de criação e posteriormente o tipo de galpão que atende as condições daquela região. Nesta revisão o intuito é trazer informações sobre os sistemas de criação e acondicionamento térmico em instalações para frangos, bem como o impacto destes sobre o bem-estar e a produção de carne. Aliando ao melhoramento genético, o manejo, a sanidade e a nutrição adequada para as aves, as instalações possuem importância significativa principalmente no quesito do conforto animal, tendo em vista que em situações que geram estresse o animal tem muita dificuldade em expressar todo seu potencial genético. Neste contexto, uma instalação adequada é essencial para trazer um retorno da produção, devem-se tomar como preocupação principal as condições ambientais dentro das instalações para as aves, por meio do controle da temperatura, da umidade relativa do ar, da radiação solar e da velocidade e qualidade do ar, esses fatores estão intimamente ligados com o bom desempenho do lote, assim, o controle do ambiente é uma das características preponderantes para garantir o conforto e bem-estar das aves e melhorar a qualidade do produto final. O objetivo desta revisão é reunir informações sobre o acondicionamento térmico para frangos de corte, possibilitando assim ter uma noção do que é importante para um bem-estar ideal.
\end{abstract}

Palavras chave: avicultura, ambiência, conforto, estresse térmico, termorregulação

\section{Breeding of broiler chickens and thermal conditioning in their facilities: Review}

Abstract. Total automation of the aviaries and constant changes in the facilities of broilers have been generated to the time of the year, and many models of sheds can be found on the field with different purposes. Being one of the most modern follow-ups of animal husbandry, the poultry industry is growing every year in terms of technology in poultry accommodation facilities. However, for each region the meteorological factors that can affect the production of the birds must be observed, and from there choose the type of shed that meets the conditions of that region. In this review the intention is to bring information 
about the breeding and thermal conditioning systems in poultry facilities, as well as their impact on welfare and meat production. In addition to genetic improvement, management, sanitation and adequate nutrition for birds, the facilities have significant importance mainly in the area of animal comfort, considering that in situations that generate stress the animal has a great difficulty in expressing all its genetic potential. In this context, a properly satisfactory return-to-production facility for improving environmental conditions within animal facilities by controlling temperature, relative humidity, solar radiation, and air velocity and quality. The control of the environment is one of the preponderant characteristics to guarantee the comfort and well-being of the birds and to improve the quality of the final product.

Keywords: poultry, ambience, comfort, thermal stress, thermoregulation

\section{Producción de pollos de corte y acondicionamiento térmico en sus instalaciones: Revisión}

Resumen. La automatización total de los aviarios y las innovaciones tecnológicas en las instalaciones de pollos de corte se han generado al principio de los años, y varios modelos de galpones se pueden encontrar en el campo con diferentes finalidades. Por ser uno de los segmentos más modernos de la cría animal la avicultura de corte crece cada año y también la búsqueda de mejoras en las instalaciones para el alojamiento de las aves. Sin embargo, para cada región se deben observar los factores meteorológicos que pueden perjudicar la producción de las aves, y a partir de ello elegir el tipo de cría y posteriormente el tipo de galpón que atiende las condiciones de esa región. En esta revisión la intención es traer informaciones sobre los sistemas de cría y acondicionamiento térmico en instalaciones para pollos, así como el impacto de éstos sobre el bienestar y la producción de carne. Al igual que el mejoramiento genético, el manejo, la sanidad y la nutrición adecuada para las aves, las instalaciones tienen una importancia significativa principalmente en lo que se refiere al confort animal, teniendo en cuenta que en situaciones que generan estrés el animal tiene mucha dificultad en expresar todo su potencial genético. En este contexto, una instalación adecuada es esencial para traer un retorno de la producción, se debe tomar como preocupación principal las condiciones ambientales dentro de las instalaciones para las aves, por medio del control de la temperatura, de la humedad relativa del aire, de la radiación solar y de la radiación solar la velocidad y la calidad del aire, estos factores están estrechamente vinculados con el buen rendimiento del lote, por lo que el control del ambiente es una de las características preponderantes para garantizar el confort y el bienestar de las aves y mejorar la calidad del producto final. El objetivo de esta revisión es reunir informaciones sobre el acondicionamiento térmico para pollos de corte, posibilitando así tener una noción de lo que es importante para un bienestar ideal.

Palabras clave: avicultura, ambiente, comodidad, estrés térmico, termorregulación

\section{Introdução}

A automatização total dos aviários e muitas inovações tecnológicas nas instalações de frangos de corte têm sido geradas ao logo dos anos e vários modelos de galpões podem ser encontrados a campo com diferentes finalidades. Por ser um dos seguimentos mais modernos da criação animal, a avicultura de corte cresce a cada ano e também a busca por melhorias nas instalações para acomodação das aves. Mas uma nova vertente que busca produtos oriundos de criações que garantem o bem-estar aos animais tem surgido.

A criação de frangos de corte, em escala industrial, é um dos setores que mais obteve progresso. A carne de frango é a mais consumida nacionalmente e a segunda mundialmente, tendo ganhado esta proporção devido a sua qualidade nutricional, variedade no preparo, por seu consumo não possuir restrições religiosas e pelo seu baixo preço no mercado, abrangendo assim maior público consumidor (Belusso \& Hespanhol, 2010). Em contrapartida, está crescendo a preocupação das pessoas com o bem- 
estar das aves nos sistemas de criação. O público acredita que os animais de produção não devem ser criados em sistemas tão intensivos, e que os animais precisam ter condições mínimas para expressar seu comportamento natural. Deste modo, a criação de frangos coloniais e orgânicos ganha destaque no mercado atual por atender um nicho específico e extremamente exigente de consumidores (Nazareno et al., 2011).

Empresas avícolas buscam aperfeiçoar as tecnologias a campo, para tornar o sistema mais eficiente, melhorar a uniformidade dos lotes e a qualidade da carne, sendo necessário que o manejo diário com as aves e as condições ambientais dentro das instalações seja adequado, proporcionando a máxima expressão do seu potencial genético (Costa et al., 2012).

Diante desses aspectos, o objetivo desta revisão é trazer informações sobre os principais sistemas de criação e acondicionamento térmico em instalações e a interferência sobre o bem-estar e a produção de frangos de corte.

\section{Fatores ambientais}

As condições climáticas são os principais fatores limitantes para a criação de frangos de corte. O Brasil possui clima tropical por estar localizado entres os trópicos de câncer e capricórnio (Köppen \& Geiger, 1928), por ser um país continental é divido em regiões, que em sua maioria possuem elevadas temperaturas e umidade do ar em grande parte do ano. A associação desses parâmetros climáticos favorece o desconforto por trazer a sensação térmica mais desagradável para os animais. Sendo assim as condições de ambiente em que as aves são alojadas são uma das principais preocupações da avicultura brasileira atual (Silva \& Vieira, 2010).

Um ambiente propício para conforto térmico dos frangos é aquele em que permite que a ave expresse todo seu potencial genético. Desta forma, os tipos de aviários interferem diretamente na produção das aves. Os aviários mais modernos são completamente automatizados com controle total de temperatura de umidade do ar. Todavia, estes apresentam elevados custos de implantação, o que faz com que muitos frangos sejam alojados em aviários convencionais onde se tem maior dificuldade em fornecer conforto térmico para as aves em todas as fases de criação (Furlan \& Macari, 2008).

A associação entre a temperatura, umidade do ar e velocidade do vento é o que fornece a sensação térmica dentro de um galpão. O que tornam desses os principais fatores que devem ser controlados para garantir a sensação térmica dos frangos. Entretanto, a relação entre esses fatores varia ao decorrer do período de vida da ave, por sua exigência em relação a necessidade de ganho ou perda de calor.

Para os pintinhos de um dia a temperatura ambiente adequada varia de $33-35^{\circ} \mathrm{C}$ (Furlan \& Macari, 2008) e com umidade relativa do ar de 65 a 70\%, e para frangos a partir dos 10 A 15 dias de idade até a idade de abate (42 dias), quando seu sistema termorregulador já está formado, a temperatura considerada ideal é de 16 a $23{ }^{\circ} \mathrm{C}$ e uma umidade relativa do ar entre 30 a 50\% (Ludtke et al., 2010). A temperatura corporal de um frango é em média $41^{\circ} \mathrm{C}$; porém, em condições ambientais extremas (de frio ou calor), as aves não conseguem manter a sua homeotermia, e isso ocorre com a alteração de em média $4{ }^{\circ} \mathrm{C}$ acima ou abaixo de sua temperatura corporal ideal pode ocasionar danos como hipertemia e hipotermia respectivamente (Cordeiro et al., 2010).

Quando as variáveis meteorológicas estão controladas, o desempenho dos frangos torna-se notoriamente eficiente. Para maior controle das variáveis do tempo as aves são alojadas em galpões, e a maioria deles são os sistemas de criação de forma intensiva que possuem diferenças quanto aos materiais de construção e tecnificação dentro do aviário.

\section{Aves}

Em respostas as condições de ambiente desconfortáveis as aves conseguem perceber as variações de temperatura do ambiente. Desta forma, são ativados no animal mudanças fisiológicas e metabólicas, conhecida como termo regulação, que serve para manter o corpo em temperatura constante favoráveis ao metabolismo normal do animal. Associado as variáveis fisiológicas ocorrem também as alterações de comportamento que também são necessárias para manter a temperatura do corpo dentro da faixa de conforto térmico, chamada de zona de termo neutralidade (Bridi, 2010; Silva et al., 2015). Esta zona de 
termo neutra está relacionada com a produção (geração de calor) ou perda (dissipação de calor) de calor do corpo do animal para o ambiente (Silva, 2000). Pode ser caracterizada por um intervalo de temperatura do corpo do animal, que depende das variações da sensação térmica no ambiente, como exposto na Tabela 1.

Tabela 1. Variações da temperatura do ambiente e delimitação da zona de frio, termo neutralidade e calor para frangos de corte

\begin{tabular}{ccccc}
\hline \multirow{2}{*}{ Temperatura } & Dias de vida & \multicolumn{3}{c}{ Variação da temperatura do ambiente $\left({ }^{\circ} \mathrm{C}\right)$} \\
\cline { 3 - 5 } & 1 à 7 & Frio & Termo neutralidade & Quente \\
\hline \multirow{2}{*}{ Necessidade de calor para } & 8 à 14 & 28 & 32 & 35 \\
a ave & 15 à 21 & 25 & 30 & 32 \\
& 22 à 35 & 20 & 28 & 30 \\
& 36 à 42 & 18 & 21 & 28 \\
\hline
\end{tabular}

Adaptado: Furlan \& Macari (2008), Abreu \& Abreu (2011).

Quando o ambiente está muito frio, o animal necessita produzir maior quantidade de calor (termogênese) quando a temperatura do ambiente está favorável ao animal não é necessário produção ou perda de calor (conforto) e quando a temperatura do ambiente está maior que o exigido pelo animal será necessário dissipar calor para o ambiente (termólise) (Bridi, 2010).

A exigência de energia de uma ave pode ser consumida apenas para o animal se manter vivo (energia de mantença) e, além disso, quando o animal começa a armazenar essa energia em forma de produção muscular (energia de produção), a energia é necessária para ocorrer reações químicas fundamentais para o crescimento e desenvolvimento de tecidos corporais (Castilho et al., 2015). Quando a ave está na zona de conforto térmico, seu organismo usa a energia de produção exclusivamente para a finalidade de produção de carne, mas quando a temperatura está fora dessa zona de conforto, tanto para o frio quanto para o calor, essa energia que seria utilizada para a produção será desviada para que o animal consiga se manter vivo, e assim o crescimento dos tecidos reduz para que sejam atendidas as mudanças fisiológicas dos frangos, para manter o corpo aquecido (Souza et al., 2015), além da diminuição do consumo de ração e consequentemente queda no ganho de peso e piora na conversão alimentar (Bridi, 2010).

\section{Troca de calor com o ambiente}

Para tentar se adaptar as mudanças de temperatura que variam durante o dia os frangos têm ações involuntárias que desencadeiam uma série de mudanças fisiológicas e comportamentais do animal. Que são diferentes dependendo da sensação térmica que os animais estão sentindo (frio ou calor).

Sensação de muito frio: baixas temperaturas podem aumentar o ganho de peso tendo em vista que as aves são melhores na retenção de calor que na dissipação, isso porque, além da camada de penas ser isolante, a genética destes animais é de origem estrangeira logo são mais adaptados a temperaturas mais baixas, entretanto, se a temperatura estiver muito baixa há uma piora acentuada na conversão alimentar já que demanda mais energia proveniente da alimentação para manter a homeostase corporal (Oliveira et al., 2016).

Sensação de muito calor: ao serem expostos a uma alta temperatura, os frangos automaticamente aumentam o consumo de água e diminuem a ingestão de alimento, pois a digestão e absorção dos nutrientes geram energia, conhecido como "incremento calórico". Alteram alguns dos seus comportamentos (Figura 1) para tentar sair da situação de desconforto.

Os principais comportamentos expressados por aves quando estão em estresse térmico são: a procura por água, deitar, cavar a cama, abrir as asas, abaixar-se próximo de paredes e bebedouros, a prostração, a ofegação (Schiassi et al., 2015). Essas são maneiras que o animal encontra para promover o resfriamento do corpo e favorecer a troca de calor com o ambiente, que ocorrem a todo o momento dependendo da intensidade do desconforto, tanto por meios sensíveis, quanto por meios latentes (Silva, 2000). 

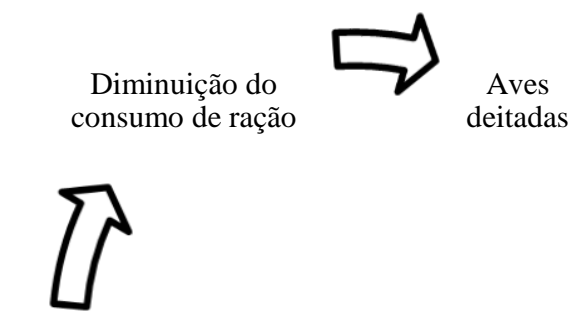

deitadas
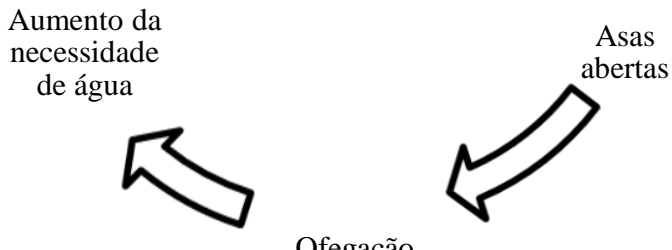

Ofegação

Figura 1. Principais ações que acontecem com as aves quando estão desconfortáveis pelo excesso de calor.

O estresse térmico afeta de forma negativa as aves devido a suas plumagens dificultarem a dissipação de calor interno, sendo assim a ave tende aumentar o fluxo sanguíneo para os tecidos periféricos como pês, cristas e barbelas (tecidos desprovidos de penas), favorecendo a dissipação de calor, esta troca é descrita como sensível e pode ser realizada por condução, mas para que ocorra é necessário ter um diferencial de temperatura entre a superfície corporal do animal e a temperatura ambiente (Bridi, 2010).

Quando o calor está mais elevado a ave aciona os meios latentes (evaporativos) de dissipação de calor, sendo as principais formas de perda de calor por evaporação que ocorrem através da pele e pelas vias respiratórias sendo essa última a mais importante forma de controle da termo regulação das aves, por não possuírem glândulas sudoríparas em sua pele (Oliveira et al., 2016; Silva \& Vieira, 2010; Staub et al., 2016).

A ofegação é uma via de perda de calor exaustiva e onerosa metabolicamente, tendo em vista que 1 grama de água pode possibilitar a eliminação de até 530 calorias (Lopes et al., 2015), quando a temperatura se eleva, a ave aumenta a frequência respiratória em até dez vezes o seu ritmo normal, essa alteração fisiológica pode acarretar em alcalose sanguínea (aumento do pH sanguíneo, devido à alta taxa de expiração de dióxido de carbono), o que pode ocasionar a morte do animal (Bueno et al., 2017). Outro fator que dificulta a troca de calor é a elevada densidade de aves por área. Na criação comercial de frangos de corte é muito importante trabalhar com densidade populacional de acordo com a capacidade da instalação (Alves et al., 2016; Andrade \& Freitas, 2018; Gundim et al., 2015). A alta densidade animal dificulta a expressão dos comportamentos que auxiliam na termorregulação, por não ter espaço na instalação e as aves não conseguem encontrar um local mais fresco, além de o contato muito próximo entre animais facilitar a troca de calor entre os indivíduos o que piora a sensação térmica e bem-estar dos frangos (Braga et al., 2018).

\section{Adaptações ambientais para frangos}

As adaptações que são obrigatoriamente realizadas nos galpões para frangos dependem da faixa de idade das aves. Em fase inicial de crescimento os pintinhos necessitam de adição de temperatura para evitar a hipotermia e na fase final os frangos necessitam de redução na temperatura do ambiente para evitar a hipertermia (Tinôco, 2001). Algumas práticas são preponderantes para evitar a hipotermia principalmente em pintinhos como o uso de aquecedores (Ferraz et al., 2017) e para aves adultas para diminuir a incidência de hipertermia as técnicas são desenvolvidas para diminuir a temperatura do ambiente, utilizando-se: ventiladores, nebulizadores, e placas evaporativas de acordo com o tipo de acondicionamento e do local (Cordeiro et al., 2010).

\section{Em fase inicial de crescimento:}

Durante os primeiros dias de vida dos pintinhos o aviário precisa de aquecimento, para que as aves consigam manter sua temperatura corporal constante (Furlan \& Macari, 2008). Nas duas primeiras 
semanas de vida a capacidade de termo regulação das aves não é bem desenvolvida (Vieira et al., 2016). Por isso, antes da chegada dos pintinhos na instalação o sistema de aquecimento já deve estar funcionando e o aviário já deve estar em uma temperatura ideal para o recebimento dos pintinhos.

A escolha do tipo de aquecimento deve ser observada quanto ao custo do produto, a capacidade em produzir calor e os efeitos que podem causar sobre a qualidade da cama e do ar (Damasceno et al., 2010). Os pinteiros devem estar montados para evitar a incidência de corrente de ar, também se tem a opção de círculos de proteção com a mesma finalidade. $\mathrm{O}$ aquecimento deve ser antes de 24 horas da chegada dos pintinhos (Pessoa et al., 2013). Os aquecedores mais utilizados no Brasil são as fornalhas à lenha que asseguram a entrada de ar quente nas instalações, podendo ser manual ou com acionamento automatizado, dispostos dentro ou fora das instalações. Quando são instalados fora do aviário facilitam o abastecimento da fornalha com lenha, sem a necessidade de entrada no galpão, evitando o risco de contaminação (Braga et al., 2018; Nonis Júnior \& Samed, 2014). Aquecimento de água quente dentro de canos sob o piso de concreto, esta troca de calor aquece a cama e consequentemente toda a área do pinteiro (Paula et al., 2014; Pessoa et al., 2013). A ventilação mínima dentro do galpão é importante para possibilitar a renovação do ar, sem a redução da temperatura dentro do aviário, instalado de maneira que a ventilação não tenha incidência direta sobre as aves (Abreu \& Abreu, 2011).

\section{Em fase final de crescimento}

Os sistemas de ventilação muitas vezes não mantêm a temperatura constante do ambiente e podem exceder o necessário, por isso os projetos mais eficientes de ventilação devem diminuir o consumo de energia e manter a qualidade do ar (Abreu \& Abreu, 2011; Menegali et al., 2013). Visando reduzir o impacto negativo do estresse térmico sobre o desempenho na produção, algumas técnicas estão sendo utilizadas para melhorar o conforto dos frangos, dentre elas estão (Abreu \& Abreu, 2011): Realizar o flushing, com a finalidade de drenar a água isto promove a diminuição da temperatura da água e remove impurezas; Retirada da comida nos horários mais quentes e fornecimento nos horários mais frescos do dia; Menor densidade de aves por área durante o inverno, (a densidade do lote deve ser compatível com a tecnificação da instalação).

\section{Sistemas de criação}

Os sistemas de criação possuem classificações de acordo com as formas de acondicionamento térmico das aves. Os atuais sistemas de criação de frangos de corte no Brasil são subdivididos em três grupos (extensivos, os semi-intesivos e os intensivos - Figura 2).

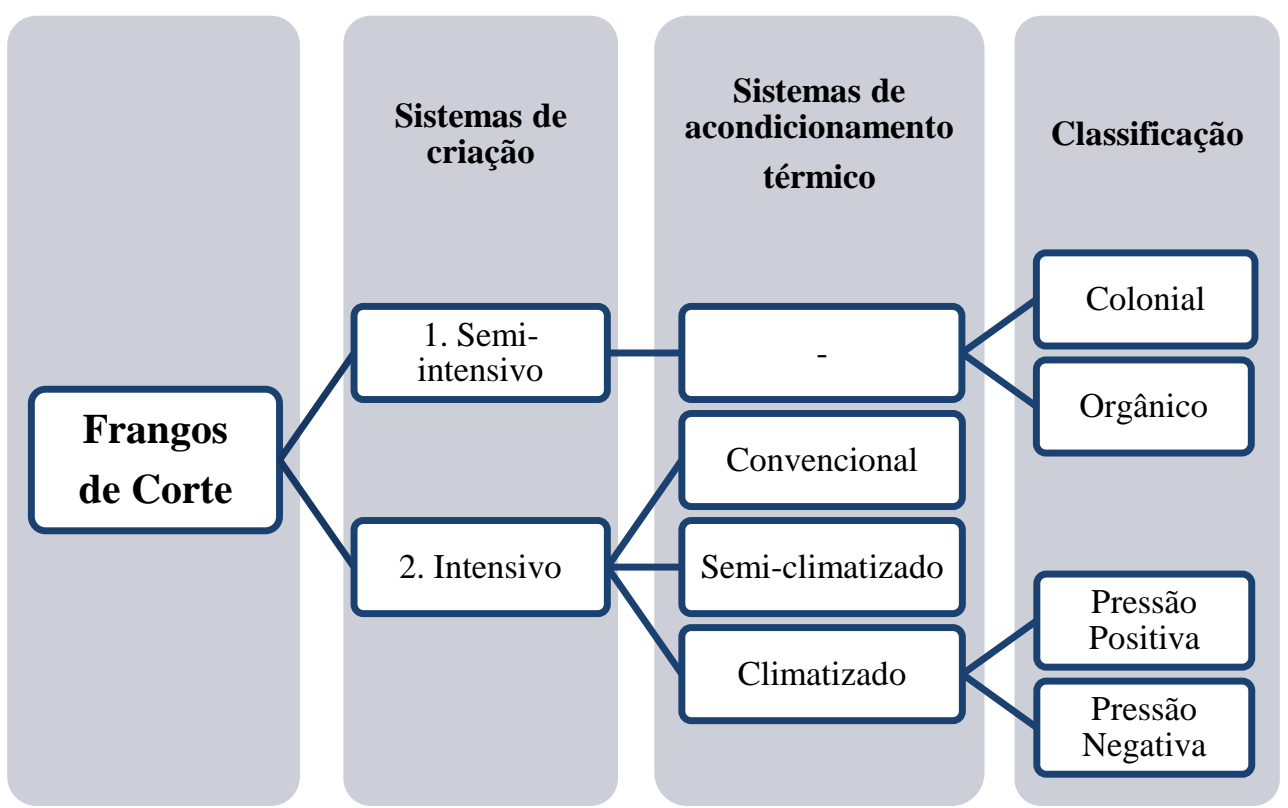

Figura 2. Principais tipos de sistemas de criação e os respectivos sistemas de acondicionamento térmico de frangos de corte no Brasil. 
Pela pressão da sociedade em procurar alternativas para adaptar as criações de frangos de corte e as leis de bem-estar animal, os sistemas semi-intensivos (colonial e orgânico) estão sendo implantados para atender um nicho de mercado específico (Oreng \& Evans, 1990).

Os sistemas de criação intensivos são altamente tecnificados o que torna a avicultura um dos mais evoluídos setores de criação animal, entretanto, a exigência do público consumidor e a preocupação da sociedade com as normas de bem-estar animal trouxe novos desafios para a avicultura industrial, por isso sistemas de criação semi-intensivos vem ganhando mercado e se destacando nacionalmente (Figueiredo, 2014).

\section{Sistema de criação semi-intensivo}

Os sistemas de criação colonial e orgânico ganham destaque, pois além de promover o bem-estar aos animais, também apresentam uma carne com menor teor de gordura e de cor amarelada, uma textura da carne mais firme e avermelhada. Em pesquisa realizada por Crabone et al. (2011) foram avaliados os fatores que influenciam a decisão de compra da carne de frango caipira, onde 64,8\% responderam que a diferença de sabor entre a carne de frango colonial e o industrial é decisivo para a escolha.

\section{Sistema de criação semi-intensivo de frango colonial}

De acordo com o Oficio Circular DOI/DIPOA nº 007/99, O.C. DIPOA No 60/99, as aves deverão permanecer em galpões confinadas até os 25 dias de idade, após deste período as aves passam a ter acesso a piquetes com forragem durante o dia (mínimo três metros quadrados de pasto por ave), onde poderão caminhar livremente e podem expressar seus comportamentos naturais, como ciscar, abrir as asas, tomar banho de terra, o que diminui o estresse (França et al., 2014). Este tipo de criação consiste na estimulação do sistema imunológico dos animais a fim de evitar o uso de medicamentos e produtos artificiais em sua dieta. A alimentação é proveniente somente de ingredientes de origem vegetal, sendo proibido o uso de alimentos de origem animal e quimioterápicos (Dias et al., 2017).

O uso de alimentos alternativos como os resíduos de monoculturas também pode ser utilizado, o que reduz o custo de produção. São utilizadas neste sistema raças (Label Rouge, New Hampshire, Sussex) ou linhagens (Carijó, Master Griss, Embrapa 041) mais rústicas.

\section{Sistema de criação semi-intensivo de frango orgânico}

O sistema orgânico de criação de frangos de corte consiste no uso de alimentação a base de produtos de origem vegetal e orgânica, sendo proibido o uso de agrotóxicos e transgênicos no cultivo destes alimentos (Azevedo et al., 2016).

As instalações da criação orgânica são simples e funcionais, o galpão deve ser constituído de piso e telhado, as laterais possuem colunas, mureta, tela, cortinas, portinhola e área dos piquetes. O piso pode ser de chão batido ou alvenaria, que facilita a limpeza do aviário, sendo que a cobertura possui a função de proteger os frangos da radiação solar e da chuva, o material do telhado pode ser de amianto, telha de barro, ou alumínio, sendo que a escolha do material depende da condição financeira do produtor e da localização do galpão (Zibetti et al., 2011). As laterais do galpão possuem colunas de suporte para a cobertura, com altura de no mínimo $2 \mathrm{~m}$ para galpões pequenos de até $20 \mathrm{~m}^{2}$ de comprimento e colunas de 2,80 m para aviários maiores. As muretas são importantes para a fixação da tela que além de proteger as aves de outros animais serve para conter a cama. As cortinas são instaladas sobre a tela com o fechamento de baixo para a cima com o uso de roldanas para facilitar o manuseio, servem para controlar a ventilação e a entrada e saída de ar no interior do aviário (Rossi \& Lemos, 2013). A porta é a via de acesso para dentro do galpão para as atividades diárias. A portinhola é a via de acesso das aves do galpão para o piquete após os 25 dias de idade, estas devem ter o tamanho ideal para facilitar a passagem, devem ser fechadas a noite depois que as aves se recolheram e aberta pela manhã. Em vista do bem-estar o sistema semi confinado é o que mais atende as necessidades das aves e há um menor índice de estresse (Pozzi \& Mundo Neto, 2017). Uma avaliação de dois sistemas de criação o intensivo e o semi-intensivo com $3 \mathrm{~m}^{2} /$ piquete/ave, o sistema semi confinado permitiu melhor acondicionamento térmico natural, com temperatura média de $24,7^{\circ} \mathrm{C}$ no ambiente externo, enquanto que o sistema confinado apresentou uma temperatura média de $26,8^{\circ} \mathrm{C}$, demonstrando que o sistema colonial apresentou um melhor 
resultado além de potencializar o bem-estar permitindo que as aves explorassem o ambiente externo (Nazareno et al., 2011).

Atualmente, os consumidores também estão preocupados com a certificação orgânica que garante a procedência do produto. A criação de frangos coloniais é normatizada pelo oficio circular DOI/DIPOA n 007/99 de 19 de maio de 1999, e o sistema orgânico é regido pela instrução normativa $n^{\circ} 46$ de 07 de outubro de 2011 (regulada pela instrução normativa número 17/2014), sendo que foi criada uma Associação Brasileira de Avicultura Alternativa, que tem como intuito o aprimoramento e padronização do sistema de criação. A atribuição de selos como "ecocert", "certificado orgânico-IBD" entre outros, garantem confiabilidade ao produto resultando em maior agregação de valor (Azevedo et al., 2016).

\section{Sistema de criação intensivo}

O sistema intensivo de criação de frangos de corte garante a acomodação de maior quantidade de animais por área, sendo mais interessantes para o produtor pela possibilidade de maior retorno financeiro. Além de serem mais tecnificados e controlados em termos de ambiência, permitem trabalhar com maior densidade animal e com linhagens mais exigentes de melhor desempenho, resultando em maior viabilidade econômica, sendo o sistema mais utilizado no Brasil atualmente (Abreu, 2010).

Acondicionamento térmico em sistemas intensivos: no sistema de criação intensiva, existem quatro tipos de acondicionamento térmico que recebem a classificação de acordo com o grau de tecnificação do galpão (Abreu \& Abreu, 2011), que estão descritos na Tabela 2, sendo eles: o sistema convencional, o semi-climatizado, o climatizado de pressão positiva e o climatizado de pressão negativa, sendo este último composto pelos aviários conhecidos como dark house e blue house.

Tabela 2. Principais características dos tipos de acondicionamento térmico para frangos de corte criados em sistemas intensivo

\begin{tabular}{|c|c|c|c|c|}
\hline \multirow{3}{*}{ Características } & \multicolumn{4}{|c|}{ Tipos de acondicionamento térmico } \\
\hline & \multirow{2}{*}{ Convencional } & \multirow{2}{*}{ Semi-climatizado } & \multicolumn{2}{|c|}{ Climatizado por pressão } \\
\hline & & & Positiva & Negativa \\
\hline Tamanho (m) & $100 \times 12$ & $125 \times 12$ & $125 \times 12$ & $125 \times 12$ \\
\hline Capacidade (aves $/ \mathrm{m}^{2}$ ) & 10,8 & 14,5 & 17 & 17 \\
\hline Entrada de ar & Sem controle & Sem controle & Controlado & Controlado \\
\hline Forro & - & Possui & Possui & Possui \\
\hline Cortinas & Possui & Possui & $\begin{array}{l}\text { Possui (fechadas ou } \\
\text { abertas) }\end{array}$ & Possui (fechadas) \\
\hline Ventiladores & - & Possui & Possui & - \\
\hline Exaustores & - & - & - & Possui \\
\hline Resfriamento $^{1}$ & - & - & $\begin{array}{c}\text { Nebulizadores (uso } \\
\text { frequente) }\end{array}$ & $\begin{array}{c}\text { placas evaporativas e pode ter } \\
\text { nebulizadores }\end{array}$ \\
\hline
\end{tabular}

${ }^{1}$ Resfriamento evaporativo. Adaptado de Mizusaki (2007) e Abreu \& Abreu (2011).

\section{Acondicionamento térmico convencional}

Este é um sistema mais simples (aviário convencional), onde não há utilização de meios artificiais de controle da temperatura, com isso, as instalações contem cortinas, podem ou não conter o forro e o condicionamento térmico é natural ou com ventiladores sem planejamento de disposição dentro da instalação (Andrade \& Freitas, 2018).

\section{Acondicionamento térmico semi-climatizado}

O sistema semi-climatizado possui na instalação forro, cortinas e ventiladores sem um planejamento prévio de implantação (transversal ou longitudinal), ou seja, não há controle sobre a entrada de ar dentro do aviário o que pode acarretar em uma má dissipação de calor dentro da instalação (Nowicki et al., 2011).

\section{Acondicionamento térmico climatizado (por pressão)}

A pressão exercida no ar e sua movimentação no interior do galpão vão depender do tipo de equipamento que está sendo utilizado como mostrado na Tabela 3. No caso das instalações climatizadas por pressão positiva são instalados ventiladores dispostos na longitudinal ou na transversal do aviário, 
já galpões por pressão negativa precisam de exaustores e são utilizados na entrada do ar por placas evaporativas (Damasceno et al., 2010).

Tabela 3. Tipo de pressão exercida para movimentação do ar no interior das instalações

\begin{tabular}{lcc}
\hline Equipamentos & Ação do equipamento & Pressão exercida \\
\hline Ventiladores & Deslocamento do ar & Positiva \\
Exaustores & Sucção do ar & Negativa \\
\hline
\end{tabular}

\section{Acondicionamento térmico climatizado por pressão positiva}

Os aviários de pressão positiva são convencionais, possuem forro, cortina e ventiladores com planejamento quanto a sua posição (transversal ou longitudinal) deste modo, o ar interno é forçado sair da instalação. Quando dispostos os ventiladores na transversal do aviário, as cortinas ficam sempre abertas, e quando dispostos na longitudinal as cortinas podem ficar abertas ou fechadas (tipo túnel). O sistema de resfriamento pode ser realizado através de nebulizadores, estes promovem a aspersão de pequenas gotículas de água no interior da instalação (Abreu \& Abreu, 2011).

\section{Acondicionamento climatizado por pressão negativa}

Os aviários que trabalham com pressão negativa são os mais modernos, podendo ser blue house ou dark house. Estes aviários possuem maior controle das condições térmicas quando comparado com os outros sistemas. Neste sistema o ar é sugado de dentro para fora da instalação por exaustores criando um vácuo parcial dentro do aviário, as cortinas permanecem sempre fechadas e precisam ter boa vedação, para que só haja entrada de ar pela placa evaporativa, isso garante uma maior eficiência dos exaustores e melhor conforto térmico dentro do galpão (Oliveira \& Gai, 2016). Na entrada do ar do aviário são instaladas placas evaporativas ( pad cooling), que geralmente são utilizados blocos cerâmicos ou painéis de celulose (mais eficiente), onde a água circula e quando o ar quente passa pela água na placa, transfere o calor para a água, evaporando-a, entrando com uma temperatura mais amena no interior do galpão (Andreazzi et al., 2018). Principalmente para esses modelos de aviários recomendase o uso de geradores de energia em caso de falta de energia, se os exaustores param de funcionar pode ocorrer desequilíbrio da temperatura interna, causando estresse excessivo e morte das aves. Uma segunda alternativa é o desarme das cortinas, sendo que em aviários dark house este deve ser gradual a fim de evitar uma entrada luminosa brusca que virá a estressar os animais (Rocha et al., 2008).

O sistema dark house se difere do blue house por possuir um controle da intensidade luminosa do galpão, onde se utiliza duas camadas de cortina preta que deve ser bem vedada a fim de evitar a entrada de luminosidade natural, o uso de light-trap (vedação da luminosidade nas entradas e saídas de ar) neste caso se torna indispensável (Rovaris et al., 2014). Os aviários mais modernos dark house estão sendo construídos com paredes de alvenaria, para que a vedação seja mais eficiente da entrada do ar e luz para dentro da instalação e garantir o isolamento térmico. Nos aviários blue house utilizam-se cortinas azuis, esta cor possui efeito calmante sobre as aves tornando-as menos agitadas, o que pode melhorar o desempenho produtivo.

\section{Características externas de construção (telhados e sombreamento natural)}

Além da escolha de um sistema de produção para as aves também são importantes os materiais a serem utilizados na instalação e a orientação da construção para atender o conforto das aves durante o período de vida. A orientação mais recomendada da instalação é leste-oeste deste modo a incidência solar tende a ficar concentrada somente sobre a cumeeira do telhado, evitando a entrada de radiação solar direta sobre o aviário (Lima et al., 2009). A cobertura do aviário deve ter grande capacidade reflexiva e isolamento térmico aos raios solares, através destas características a radiação solar terá dificuldades em atravessar o material, caso contrário, irá ocorrer um maior aquecimento do aviário em temperaturas mais elevadas. Existem vários tipos de coberturas encontradas no mercado, entre elas: fibrocimento, alumínio, galvanizada, telha de barro e termo acústica (Rocha et al., 2008).

Abaixo está relacionado alguns materiais que podem ser utilizados para a cobertura das instalações e suas características: 
Telha de fibrocimento: esquenta muito ao sol, porém sua construção é fácil e possui pouco custo de aquisição/instalação.

Telha de alumínio: está mais susceptível a danos por ventos, chuvas e granizos. Nestes casos torna-se barulhenta e acarreta estresse aos animais, por isso sua utilização deve ser planejada e também deixa a desejar se houver oxidação.

Telha galvanizada: dentre estas é a que apresenta um pior desempenho na mantença do conforto térmico, no entanto tem uma durabilidade alta e é pouco dispendiosa.

Telha de barro: possui grande eficiência, quando chove esta absorve a água tornando-se pesada e quebradiça podendo ocasionar infiltrações.

Telha termo acústica: pode ser também chamada de telha sanduíche, consistem em uma camada de isopor recoberta por duas folhas de telha de zinco, que permite o isolamento térmico e acústico do aviário.

A junção de coberturas a mateiras como poliuretano e poliestireno podem melhorar consideravelmente os resultados na isolação térmica. Utilizar forros sobre a cobertura reduz a transferência de calor para dentro da construção, por fora também se pode pintar a cobertura com cor branca para permitir maior refletância dos raios solares (Souza et al., 2015).

Ainda para diminuir a incidência de raios solares para dentro da instalação, plantar grama e árvores ao redor do aviário. O gramado diminui substancialmente a radiação, e concomitante, reduz a sensação térmica no interior do galpão (Tinôco, 2001).

O sombreamento ao redor da instalação deve ser com o plantio de árvores não frutíferas, para que não haja a atração de insetos, outros animais e aves silvestres para próximo do aviário. Elas devem ser plantadas a uma distância de duas vezes a altura da construção para que não caia galhos sobre as instalações ou haja entupimento de calhas.

\section{Qualidade do ar e da cama no interior das instalações}

A qualidade do ar bem como a da cama do aviário são fatores a ser considerado, o ar além de ser fonte de oxigênio para as aves, é necessário no metabolismo de qualquer animal é também excelente meio para a dissipação do calor excedente, do vapor d'agua proveniente de nebulizadores, dos gases provindos dos animais e da poeira liberada pela cama, entre outros (Curi et al., 2016).

No caso das instalações para frangos de corte o gás amônia $\left(\mathrm{NH}_{3}\right)$, o dióxido de carbono $\left(\mathrm{CO}_{2}\right)$ e o monóxido de carbono (CO), são os que mais afetam a qualidade do ar. Geralmente $\mathrm{o} \mathrm{NH}_{3}$ é exposto como um gás poluente e tóxico, encontrado no interior das instalações em altas concentrações, sua formação é devido a decomposição microbiana do ácido úrico presente nas excretas, podendo ser detectado por humanos em uma concentração de $10 \mathrm{ppm}$. $\mathrm{O} \mathrm{NH}_{3}$ é um gás menos denso que o ar o que faz com que ele se movimente com facilidade pela instalação (Silva et al., 2018). O gás carbônico é inodoro sendo produzido pelos próprios animais e também pela queima de combustíveis em sistemas de aquecimento, encontrado em média numa concentração de 900 ppm, é perigoso e se encontra presente nos galpões principalmente em épocas frias, sendo que nas primeiras semanas de vida das aves onde o uso de aquecedores se faz necessário, o limite máximo em um aviário recomendado é de 10 ppm (Santos et al., 2009).

Já a qualidade da cama é imprescindível para que a ave tenha um desempenho e crescimento ideal, tendo em vista que fica em contato direto grande parte do tempo. Na escolha de um tipo de material eficaz para ser utilizado como cama alguns fatores devem ser levados em consideração como: tamanho de partícula, capacidade de retenção de umidade e excretas, compactação, isolação térmica, evaporação da água, presença de poeira e contaminantes e também deve proporcionar ao animal um local macio e confortável para que sejam evitados problemas como calo de peito, lesões de joelho e coxim plantar, o que pode acarretar perdas econômicas por condenação da carcaça nos abatedouros além de comprometer o bem-estar (Vieira et al., 2015). 
A cama por ser de material orgânico, pode possibilitar a proliferação de fungos tóxicos aos animais, como por exemplo, os fungos do gênero Aspergillus, para que isso seja evitado é necessário um manejo de revolvimento da cama durante o alojamento do lote (entre 30 dias de idade), a fim de mantê-la sempre macia, solta e seca. A qualidade da cama e o pH estão proporcionalmente ligados com a qualidade do ar pois quanto maior a umidade da cama, maior a liberação de amônia nos galpões de produção, e a liberação da amônia é minimizada quando se encontra um pH abaixo de 7,0 (Carvalho et al., 2011). A reutilização da cama ao término de um lote por parte de empresas e produtores, é uma prática frequente em diversos países, inclusive no Brasil. Essa prática é realizada com o intuito de diminuir custos sobre a produção, sendo que para ser utilizada de maneira não prejudicial as aves, está deve passar por tratamento químico ou biológico a fim de que a carga microbiana seja reduzida ou inativada, evitando que patógenos prejudiciais passem de um lote para o outro. Os métodos mais utilizados no Brasil são a adição de cal (método químico) e a fermentação da cama em leira (método biológico) (Vieira et al., 2015).

No método de fermentação, a cama é alinhada e empilhada no centro do aviário, removendo as camas das beiradas e em volta dos pilares, após é coberta com lona em toda a sua extensão, sendo mantida coberta por 10 à 12 dias (período equivalente a fermentação). Já no método de adição de cal, é colocado cal em toda a extensão da cama, feito o revolvimento para a incorporação do produto e o alojamento das aves pode ser feito de 2 a 3 dias depois. Nos dois métodos é necessário o revolvimento prévio, retirada de placas (compactada), locais com excesso de umidade e então é usado lança-chamas para a queima das penas. O reuso de cama é recomendável por até seis lotes, ou seja, uma troca de cama por ano e somente em lotes saudáveis (Campos et al., 2018). Mesmo que a reutilização seja usual, uma pesquisa realizada por Baracho et al. (2013), onde os autores avaliaram o ambiente interno de dois galpões de frangos em relação ao uso de cama nova e reutilizada, foi obtido como conclusão que em relação ao conforto térmico das aves não houve diferenças significativas, no entanto a temperatura da cama encontrou-se mais elevada naquela que estava sendo reutilizada, isto pode acarretar um ambiente mais estressante para as aves.

Deste modo, realizar a avaliação dos sistemas de ventilação é importante para garantir o bem-estar e saúde das aves e dos trabalhadores dentro do aviário em relação ao conforto térmico e qualidade da cama e do ar, fazendo com que possa se obter informações para se alterar o manejo caso se faça necessário, sendo que uma concentração elevada desses gases pode vir a acarretar problemas respiratórios, irritabilidade ocular e dermatites nas aves (Vigoderis et al., 2010).

A escolha do sistema de criação ideal depende da região onde será implantada a instalação e o objetivo da produção. No cenário atual, as produções de frangos colonial e orgânicos vêm tomando espaço para um público exigente, entretanto, os frangos ainda vão continuar sendo criados em sistemas intensivos para permanecer com a exportação, mas a preocupação com o bem-estar das aves tem crescido substancialmente.

\section{Referências bibliográficas}

Abreu, V. M. N. \& Abreu, P. G. (2011). Os desafios da ambiência sobre os sistemas de aves no Brasil. Revista Brasileira de Zootecnia, 40(256):1-14.

Abreu, V. N. (2010). Desafios da pesquisa frente aos novos sistemas de produção. Avicultura Industrial, 520-29.

Alves, M. G. M., Freitas Albuquerque, L. \& Batista, A. S. M. (2016). Qualidade da carne de frangos de corte. Essentia-Revista de Cultura, Ciência e Tecnologia da UVA, 17(2):64-86.

Andrade, L. \& Freitas, E. S. (2018). Efeitos da densidade populacional sobre o desempenho produtivo em frangos de corte em diferentes tipos de aviários. Arquivos Brasileiros de Medicina Veterinária, 1(1):1-6.

Andreazzi, M. A., Pinto, J. S., Santos, J. M. G., Cavalieri, F. L. B., Matos, N. C. S. \& Barbieri, I. O. (2018). Desempenho de frangos de corte criados em aviário convencional e dark-house. Revista da Universidade Vale do Rio Verde, 16(1):1-6.

Azevedo, G. S., Souza, J. P. L., Cardoso, J. A., Araujo, P. H. H., Santos Neta, E. R. \& Novas, M. P. V. (2016). Produção de aves em sistema orgânico. PUBVET, 10(4):327-333. 
Baracho, M. S., Cassiano, J. A., Nääs, I. A., Tonon, G. S., Garcia, R. G., Royer, A. F. B., Santana, M. R. (2013). Ambiente interno em galpões de frango de corte com cama nova e reutilizada. Agrarian, 6(22):473-478.

Belusso, D. \& Hespanhol, A. N. (2010). A evolução da avivultura industrial brasileira e sues efeitos territorias. Revista Percurso, 2(1):25-51.

Braga, J. S., Macitelli, F., Lima, V. A. \& Diesel, T. (2018). O modelo dos “Cinco Domínios" do bemestar animal aplicado em sistemas intensivos de produção de bovinos, suínos e aves. Revista Brasileira de Zoociências, 19(2):204-226.

Bridi, A. M. (2010). Adaptação e aclimatação animal. Londrina, Paraná, Brasil: Eduel.

Bueno, J. P. R., Nascimento, M. R. B. M., Martins, J. M. S., Marchini, C. F. P., Gotardo, L. R. M., Sousa, G. M. R., Rinaldi, F. P. (2017). Influência da idade e do estresse cíclico de calor no perfil bioquímico sérico em frangos de corte. Semina: Ciências Agrárias, 38(3):1383-1392.

Campos, M. F. F. S., Teófilo, T. S., Chaves, D. P., Santos, A. C. G., Lopes, B. C. A., Bezerra, N. P. C. \& Torres, M. A. (2018). Identificação parasitológica da cama de frango reutilizada em uma granja avícola. Revista Brasileira de Ciência Veterinária, 25(1).

Carvalho, T. M. R., Moura, D. J., Souza, Z. M., Souza, G. S. \& Freitas Bueno, L. G. (2011). Qualidade da cama e do ar em diferentes condições de alojamento de frangos de corte. Pesquisa Agropecuária Brasileira, 46(4):351-361.

Castilho, V. A. R., Garcia, R. G., Lima, N. D. S., Nunes, K. C., Caldara, F. R., Nääs, I. A., Jacob, F. G. (2015). Bem-estar de galinhas poedeiras em diferentes densidades de alojamento. Revista Brasileira de Engenharia de Biossistemas, 9(2):122-131.

Cordeiro, M. B., Tinôco, I. F. F., Silva, J. N., Vigoderis, R. B., Pinto, F. A. C. \& Cecon, P. R. (2010). Conforto térmico e desempenho de pintos de corte submetidos a diferentes sistemas de aquecimento no período de inverno. Revista Brasileira de Zootecnia, 39(1):217-224.

Costa, E. M., Dourado, L. R. B. \& Merval, R. R. (2012). Medidas para avaliar o conforto térmico em aves. PUBVET, 61450-1454.

Crabone, G. T., Moori, R. G. \& Sato, G. S. (2011). Fatores relevantes na decisão de compra de frango caipira e seu impacto na cadeia produtiva. Organizações Rurais \& Agroindustriais, 7(3):312-323.

Curi, T. M. R. C., Vercellino, R. D. A., Massari, J. M., Souza, Z. M. \& Moura, D. J. (2016). Geoestatística para avaliação do controle ambiental do sistema de ventilação em instalações comerciais para frangos de corte. Engenharia Agrícola, 34(6):1062-1074.

Damasceno, F. A., Yanagi Junior, T., Lima, R. R., Gomes, R. C. C. \& Moraes, S. R. P. (2010). Avaliação do bem-estar de frangos de corte em dois galpões comerciais climatizados. Ciência Agrotecnologia, 34(4):1031-1038.

Dias, A. N., Maciel, M. P., Aiura, A. L. O., Arouca, C. L. C., Silva, D. B. \& Moura, V. H. S. (2017). Linhagens de frangos caipiras criadas em sistema semi-intensivo em região de clima quente. Pesquisa Agropecuária Brasileira, 51(12):2010-2017.

Ferraz, P. F. P., Junior, T. Y., Ferraz, G. A. S. \& Damasceno, F. A. (2017). Distribuição espacial do índice de temperatura do globo e umidade em galpão de frangos na primeira semana de vida aquecido por fornalha industrial. Energia na Agricultura, 32(4):356-363.

Figueiredo, P. A. E. (2014). Avicultura agroecológica é possível. Revista CRMV, 611-5.

França, É. C., Assis, A. S., Lopes, F. B., Minharro, S., Rosa, F. C. \& Ferreira, J. L. (2014). Caracterização fenotípica e fatores de decisão na compra de frango caipira no município de araguaína, tocantins. Enc bios, 10(18):840-851.

Furlan, R. L. \& Macari, M. (2008). Fisiologia aviária aplicada a frangos de corte. Termorregulação (Vol. 1). Jaboticabal, São Paulo, Brasil Funep. .

Gundim, L. F., Rodrigues, E. A., Blanca, W. T., Coleto, A. F. \& Medeiros, A. A. (2015). Causas de condenações de frangos de corte relacionadas a manejo e ambiência. Enciclopédia Biosfera, 11(21):515-522. 
Köppen, W. \& Geiger, R. (1928). Klimate der Erde. Gotha: Verlag Justus Perthes. Wall-map $150 \mathrm{~cm} \times 200 \mathrm{~cm}$.

Lima, J. A. K., Alves, J. A. K., Araújo, C. V., Manno, M. C., Jesus, M., Fernandes, L. D. \& Tavares, F. (2009). Avaliação do ambiente térmico interno em galpões de frangos de corte com diferentes materiais de cobertura na mesorregião metropolitana de Belém. Revista de Ciências Agrárias, 513750.

Lopes, J. C. O., Ribeiro, M. N. \& Lima, V. (2015). Estresse por calor em frangos de corte. Revista Eletrônica Nutri-Time, 124478-4487.

Ludtke, C. B., Silveira, E. T. F., Bertoloni, W., Andrade, J. C., Buzelli, M. L. T., Bressa, L. R. \& Soares, G. J. D. (2010). Bem-estar e qualidade de carne de suínos submetidos a diferentes técnicas de manejo pré-abate. Revista Brasileira de Saúde e Produção Animal, 11(1):231-241.

Menegali, I., Tinoco, I. F. F., Carvalho, C. C. S., Souza, C. F. \& Martins, J. H. (2013). Comportamento de variáveis climáticas em sistemas de ventilação mínima para produção de pintos de corte. Revista Brasileira de Engenharia Agrícola e Ambiental-Agriambi, 17(1):106-113.

Mizusaki, M. Y. (2007). Reestruturação produtiva na avicultura em Mato Grosso do Sul. Geosul, 22(44):135-154.

Nazareno, A. C., Pandorfi, H., Guiselini, C., Vigoderis, R. B. \& Pedrosa, E. M. R. (2011). Bem-estar na produção de frango de corte em diferentes sistemas de criação. Engenharia Agrícola, 31(1):13-22.

Nonis Júnior, J. \& Samed, M. M. A. (2014). Análise da eficiência energética em um aviário de corte. Revista Produção Industrial \& Serviços, 1(1):74-92.

Nowicki, R., Butzge, E., Otutumi, L. K., Piau Júnior, R., Alberton, L. R., Merlini, L. S., Caetano, I. C. S. (2011). Desempenho de frangos de corte criados em aviários convencionais e escuros. Arquivos de Ciências Veterinárias e Zoologia da UNIPAR, 14(1):25-28.

Oliveira, L. P. \& Gai, V. F. (2016). Desempenho de frango de corte em aviários convencional e aviários dark house. Revista cultivando o saber, 993-101.

Oliveira, P. M., Faria Júnior, M. J. A. \& Garcia Neto, M. G. (2016). Estratégias para minimizar os efeitos de um ambiente térmico adverso para frangos de corte. Arquivo Brasileiro de Medicina Veterinária e Zootecnia, 68(3):739-747.

Oreng, R. E. \& Evans, J. S. (1990). Ciência e produção de aves: aquecimento, criação, alojamento, equipamentos e produção de aves. São Paulo: Roca143-178.

Paula, M. O., Sá, L. V., Carvalho, S. O. \& Tinôco, I. (2014). Análise do conforto térmico e do desempenho animal em galpão para frango de corte na fase inicial de vida. Enciclopédia Biosfera, 10(18):236-250.

Pessoa, G. T., Sousa, G. V., Ferraz, M. S., Feitosa, M. L. T. \& Sampaio, A. M. (2013). Estratégias inovadoras no manejo de frangos de corte em avicultura industrial: fases pré-inicial, inicial, engorda e final. PUBVET, 71002-1136.

Pozzi, G. J. R. \& Mundo Neto, M. (2017). Conflitos entre a produção orgânica em grande escala e a agroecologia. Revista Interface Tecnológica, 14(1):332-347.

Rocha, J. S. R., Lara, L. J. C. \& Baião, N. C. (2008). Produção e bem-estar animal: aspectos éticos e técnicos da produção intensiva de aves. Ciência Veterinária nos Trópicos, 11(1):49-55.

Rossi, G. A. M. \& Lemos, P. P. L. (2013). Comparação da produção animal entre os sistemas orgânico e o convencional. Revista de Educação Continuada em Medicina Veterinária e Zootecnia do CRMV$S P, 11(1): 6-13$.

Rovaris, E., Corrêa, G. d. S. S., Corrêa, A. B., Junior, J. G. C., Luna, U. V. \& Assis, S. D. (2014). Avaliação da incubação artificial de ovos deformados em matrizes pesadas. PUBVET, 8(18):21732291.

Santos, P. A., Baeta, F. C., Tinôco, I. F. F., Albino, L. F. T. \& Cecon, P. R. (2009). Ventilação em modos túnel e lateral em galpões avícolas e seus efeitos no conforto térmico, na qualidade do ar e no desempenho das aves. Ceres, 56(2):172-180. 
Schiassi, L., Yanagi Júnior, T., Ferraz, P. F. P., Campos, A. T., Silva, G. R. \& Abreu, L. H. P. (2015). Comportamento de frangos de corte submetidos a diferentes ambientes térmicos. Engenharia Agrícola, 35(3):390-396.

Silva, I. \& Vieira, F. (2010). Ambiência animal e as perdas produtivas no manejo pré-abate: o caso da avicultura de corte brasileira. Archivos de Zootecnia, 59113-131.

Silva, L. F., Menegali, I., Ferreira, F., Santos, E. V., Rippel, D. N., Albano, L. B., Vieira, A. K. J. (2018). Avaliação da qualidade do ar em instalações avícolas. Caderno de Ciências Agrárias, 10(1):68-72.

Silva, M. G., Martin, S., Oliveira, C. E. G., Moscon, E. S. \& Damasceno, F. A. (2015). Desempenho térmico de tipos de coberturas no interior de modelos reduzidos de galpões avicolas. Energia na Agricultura, 30(3):269-275.

Silva, R. G. (2000). Introdução à bioclimatologia animal. São Paulo, Brasil: Nobel.

Souza, B. B., Silva, R. C., Rodrigues, L. R., Rodrigues, V. P. \& Arruda, A. S. (2015). Análises do efeito do estresse térmico sobre produção, fisiologia e dieta de aves. Agropecuária Científica no Semiárido, 11(2):22-26.

Staub, L., Moares, M. D. G., Santos, M. G., Komiyama, C. M., Gonçalves, N. S., Fernandes Junior, R. B., Roque, F. A. (2016). Ambiência interna e externa em galpão de frangos de corte nas diferentes épocas do ano e fases de criação. Nativa, 4(3):128-133.

Tinôco, I. F. F. (2001). Avicultura industrial: novos conceitos de materiais, concepções e técnicas construtivas disponíveis para galpões avícolas brasileiros. Revista Brasileira de Ciência Avícola, $3(1): 1-25$.

Vieira, F. M. C., Silva, I. J. O. d., Nazareno, A. C., Faria, P. N. \& Miranda, K. O. S. (2016). Termorregulação de pintos de um dia submetidos a ambiente térmico simulado de transporte. Arquivo Brasileiro de Medicina Veterinária e Zootecnia, 68(1):208-214.

Vieira, M. F. A., Tinoco, I. F. F., Santos, B. M., Inoue, K. R. A. \& Mendes, M. A. S. A. (2015). Caracterização e análise da qualidade sanitária de camas de frango de diferentes materiais reutilizados sequencialmente. Engenharia Agrícola, 35(5):800-807.

Vigoderis, R. B., Cordeiro, M. B., Tinôco, I. d. F. F., Menegali, I., Souza Júnior, J. P. \& Holanda, M. C. R. (2010). Avaliação do uso de ventilação mínima em galpões avícolas e de sua influência no desempenho de aves de corte no período de inverno. Revista Brasileira de Zootecnia, 39(6):13811386.

Zibetti, A. P., Corrêia, A. F. \& Signor, A. A. (2011). Agropecuária orgânica como alternativa de desenvolvimento sustentável. Toledo, Paraná, Brasil: GFM Gráfica e Editora.

Recebido: 1 de fevereiro, 2019.

Aprovado: 22 de fevereiro, 2019.

Publicado: 6 de março, 2019.

Licenciamento: Este artigo é publicado na modalidade Acesso Aberto sob a licença Creative Commons Atribuição 4.0 (CC-BY 4.0), a qual permite uso irrestrito, distribuição, reprodução em qualquer meio, desde que o autor e a fonte sejam devidamente creditados 